\title{
Assessment of isokinetic muscle function in Korea male volleyball athletes
}

\author{
Chang-Gyun Kim, Bog Ja Jeoung* \\ Departmnt of Sports \& Leisure Studies, Gachon University, Seongnam, Korea
}

Volleyball players performed numerous repetitions of spike actions, which uses and requires strong and explosive force, and control of the muscles of the shoulder, lower back, and legs. Muscle imbalance is one of the main causes of sport injuries. The purpose of this study was to assess isokinetic muscle functions in male volleyball players. We thus aim to accurately evaluate their muscle functions, and identify the best training strategy to achieve optimal muscle strength balance in future training programs. The participants in this study consisted of 14 male volleyball players. Muscle strength was measured using the isokinetic dynamometer. Muscle strength was evaluated in terms of peak torque and average power, calculated from five repeated measurements at an angular speed of $60^{\circ} / \mathrm{sec}$. Three players who were left attackers showed shoulder imbalance, four players showed trunk joint imbalance, nine players had knee joint of extension/flexion imbalance and four players showed left/right imbalance. The results showed that the number of volleyball players with differences between the strength of the bilateral knee muscles, and between the strength of the hamstrings and quadriceps muscles was higher than the number of players with differences between the strength of the shoulder internal and external rotation muscles, and higher than the number of players with differences between the strength of the lower back extension and flexion muscles.

Keywords: Assessment, Isokinetic, Volleyball, Athletic

\section{INTRODUCTION}

Volleyball is a sport played in a relatively small court $(9 \mathrm{~m} \times 9$ $\mathrm{m})$, inside which the players perform fast movement and repeated high vertical jumping in a very short time. During a volleyball match, the players are required to serve, pass, and set the ball, as well as to spike and attack. Among those actions, spiking and attacking demand intense vertical jumping and landing.

During volleyball matches, when numerous repetitions of the aforementioned movements are performed, the anaerobic type of exercise is the most frequently performed activity, with a ratio to aerobic exercises of 7:3 (Lamb, 1984). Playing volleyball also requires agility and fast reaction time in order to prevent the ball from touching the floor. A good muscle strength ratio between dominant and nondominant sides, and between antagonist and agonist muscles, especially of the knee joint, is ultimately important for sports in order to have stability of the lower limbs and to prevent knee injury (Agaard et al., 1998; Bahr and Krosshang, 2005). Since muscle imbalance is one of the main causes of sport injuries, the assessment of the muscle function is very important for designing injury prevention programs.

The hamstrings (flexion) and the quadriceps femoris (extension) muscles are the key effectors during high performance activities during sports, such as running and jumping (Jespersen et al., 2000). Most of the lower limb movements require strong bilateral muscle contractions (MacLaren, 1990). For volleyball it is important to have balanced muscle strength development in both legs (Brooks and Fahey, 1987; Thorstensson et al., 1976), with minimal differences regarding muscle strength between the dominant and nondominant legs. Further, the ratio between the muscle strengths of the hamstring and of the quadriceps $(\mathrm{H} / \mathrm{Q})$ should be low for volleyball.

Moreover, during a spike action, the muscles of the legs, lower back, and knees are used in an explosive manner in order to gener-
${ }^{*}$ Corresponding author: Bog Ja Jeoung (ib http://orcid.org/0000-0002-7144-6179 Department of Sports \& Leisure Studies, Gachon University, 1342, Seongnamdaero, Sujeong-gu, Seongnam 13120, Korea

Tel: +82-32-820-4766, Fax: +82-32-820-4350, E-mail: bogja05@gachon.ac.kr Received: August 2, 2016 / Accepted: September 20, 2016
This is an Open Access article distributed under the terms of the Creative Commons Attribution Non-Commercial License (http://creativecommons.org/licenses/by-nc/4.0/) which permits unrestricted non-commercial use, distribution, and reproduction in any medium, provided the original work is properly cited. 
ate a strong force, which requires effective control of the entire body in order to prevent injury. In other words, an ideal training method for volleyball would have to train the simultaneous control of the lower back, knees, and legs.

As it was previously reported, the spike and serving motions of volleyball require such dynamic stabilization in order to maintain the integrity of the glenohumeral joint (Aagaard and Jørgensen, 1996; Bahr and Krosshang, 2005). Stability of the glenohumeral joint during the acceleration, deceleration, and follow-through phases of striking is maintained by the rotator cuff muscles acting eccentrically, compressing the humeral head. Thus, active and passive mechanisms work to maintain dynamic stability and compression of the humeral head within the glenoid fossa during spiking and serving. A study by Aagaard et al. (1997) investigated knee injury in 295 Danish volleyball players and found that $55 \%$ of the players had experienced knee injury at least once, while $48 \%$ responded as having chronic knee injury. Players with 11.5 years of experience are in a group with increased risk of overuse injuries (Seminati and Minetti, 2013).

Further, a previous study showed that, for achieving good performances during powerful spikes and servings, cooperative harmony between the hamstrings, quadriceps, shoulder, and lower back muscles (Chung et al., 1987; Han et al., 2011). Specially, volleyball attackers exhibit increased risk for back injuries due to increased spinal twisting, flexing, lateral bending, and asymmetrical movements. In general, low back injuries are associated with dysfunctions regarding trunk muscle coactivation or recruitment patterns, not with reduced strength (Seminati and Minetti, 2013).

Isokinetic assessment can be used to measure torque values at several joint of the body. This assessment typically involves comparing the joint of interest with the corresponding contralateral joint. Isokinetic testing evaluates the torque generated during the exercise, allowing for an assessment of strength and functional ability, for a comparison of different muscles.

The objective of the present study was to assess isokinetic muscle functions in male volleyball players of the Korean national volleyball who is preparing for the 2020 Tokyo Olympics. We thus aim to accurately evaluate their muscle functions, and identify the best training strategy to achieve optimal muscle strength balance in future training programs.

\section{MATERIALS AND METHODS}

\section{Participants}

The participants in the present study consisted of 14 male vol-
Table 1. Baseline characteristics of the study participants $(n=14)$

\begin{tabular}{lcccc}
\hline No. & Height $(\mathrm{cm})$ & Weight $(\mathrm{kg})$ & Experience $(\mathrm{mo})$ & Position \\
\hline V1 & 192.2 & 85.2 & 120 & $\mathrm{~L}$ \\
V2 & 200 & 87.7 & 86 & $\mathrm{~L}$ \\
V3 & 186 & 84.5 & 96 & $\mathrm{~L}$ \\
V4 & 188 & 76.3 & 69 & $\mathrm{~L}$ \\
V5 & 191 & 82.3 & 122 & $\mathrm{R}$ \\
V6 & 182.9 & 78.2 & 135 & $\mathrm{Li}$ \\
V7 & 186.4 & 76.5 & 150 & $\mathrm{~S}$ \\
V8 & 194.8 & 85 & 125 & $\mathrm{R}$ \\
V9 & 188.3 & 77.9 & 136 & $\mathrm{~S}$ \\
V10 & 201.9 & 100 & 41 & $\mathrm{C}$ \\
V11 & 188.3 & 83.3 & 137 & $\mathrm{~L}$ \\
V12 & 207.8 & 99.8 & 84 & $\mathrm{C}$ \\
V13 & 199.8 & 85.4 & 120 & $\mathrm{~L}$ \\
V14 & 203.2 & 82.6 & 17 & $\mathrm{~L}$ \\
Mean \pm SD & $193.69 \pm 7.6$ & $84.76 \pm 8.09$ & $103.14 \pm 39.6$ &
\end{tabular}

The volleyball players' position codes are: $C$, center; L, left; Li, libero; $R$, right; $S$, setter. $\mathrm{V}$, volleyball player; SD, standard deviation.

leyball players, aged 16-26 years, who are members of the Korean national volleyball team preparing for the Tokyo Olympics in 2020. The participants self-reported their play position, dominant leg and shoulder, length of their volleyball career, and age. Anthropometric measurements (Table 1) included height, body weight (BW), muscle mass, and body composition, and were performed using Inbody2 (Inbody 670, Seoul, Korea). The mean volleyball playing experience among the study participants was 103.14 \pm 39.6 months (range, 17-148 months). The mean height, weight, and age were $193.69 \pm 7.6 \mathrm{~cm}$ (range, 182.9-207.8 cm), $84.76 \pm 7.47 \mathrm{~kg}$ (range, $76.3-100 \mathrm{~kg}$ ), and $20.7 \pm 1.8$ years (range, $18-25$ years), respectively.

All participants had previously undergone isokinetic testing. They had no history of surgery of the knee, shoulder, or trunk. All measurements were taken regardless of injury status. Before testing, the participants completed a nonspecific, 5-min warm-up on a stationary bicycle ergometer at a self-regulated, low-to-moderate intensity, followed by $10 \mathrm{~min}$ of dynamic stretching that targeted the main muscle group being tested. The warm-up routine was performed under the supervision of a examiner.

\section{Procedures}

In the present study, muscle strength was measured using the isokinetic dynamometer (Cybex International Inc., New York, NY, USA) at the Department of Exercise Rehabilitation and Welfare, Gachon University. All measurements were performed by a examiner with 5 years of experience, during a single test session. 
Muscle strength was evaluated in terms of peak torque and average power, calculated from five repeated measurements at an angular speed of $60^{\circ} \mathrm{sec}$. To allow comparisons in terms of maximum muscle strength in the shoulder, knee, and lumbar joints, the peak torque was normalized by BW (PTBW, percent of torque produced per $\mathrm{kg}$ of BW).

Muscle strength in the shoulder was measured on the dominant side, while the shoulder's internal rotation and external rotation (peak torque, expressed in units of $\mathrm{Nm}$ ) were measured for the striking arm, i.e., the shoulder that the participant reported to be using most frequently for hitting or serving the ball during the game (Stickley et al., 2008). The measurements were taken with the participants in a seated modified neutral position, with $90^{\circ}$ of elbow flexion, $30^{\circ}$ of glenohumeral joint flexion, and $30^{\circ}$ of glenohumeral abduction; during the measurements, the participants wore stabilization straps across the hip and upper body.

The H/Q ratios for the right and left knee were measured on an adjustable dynamometer chair, with the participants comfortably seated with the hip joint at approximately $75^{\circ}$ of flexion (where $0^{\circ}$ represents full extension). The participants wore straps, and the shoulders were fixed in ventral-dorsal and cranial-caudal direction using shoulder pads. For further stabilization of the upper body during the test session, the participants were instructed to hold the handgrips located on the side of the chair. The measurement was taken with the participants performing concentric flexion and extension with their knees.

Trunk strength was measured between the 4th and 5th lumbar vertebrae, where the extension of the iliac crest meets the spine. Using this position as the reference, the footplate of the isokinetic dynamometer was adjusted to accommodate comfortable depth and height for each participant. The participants stood on the footplate, and pads were placed and fixed on the chest (below the clavicle), thighs, and below the knees. Subsequently, the participants were instructed to hold both handgrips located in front of their chest. The dynamometer used in our study was designed to enable trunk flexion and extension movements in an up-right position, with the feet positioned on two horizontal footplates, and the knees in a slightly flexed position $\left(10^{\circ}-20^{\circ}\right)$. We measured trunk strength during trunk flexion from $-10^{\circ}$ to $50^{\circ}$, and during trunk extension from $50^{\circ}$ to $-10^{\circ}$ (Davies and Gould, 1982; Guilhem et al., 2014).

\section{Data analysis}

The raw data for assessment and diagnosis of isokinetics and function of the shoulders, lower back, and knees were organized using Excel 2010 (Microsoft Corp., Redmond, WA, USA). The results are given as mean \pm standard deviation and range.

\section{RESULTS}

Tables 2, 3, and 4 show the results regarding muscle strength of the shoulders, knees, and lower back in members of the male Korean national volleyball team preparing for the Tokyo Olympics in 2020.

With respect to the isokinetic muscle function in the shoulder, the lowest PTBW was noted for the athletes with the shortest volleyball experience (PTBW was 101 and $104 \mathrm{Nm} / \mathrm{kg}$ for participants V10 and V14, respectively), while the highest PTBW (149 $\mathrm{Nm} / \mathrm{kg}$ ) was noted for participant V13. When considering the playing position, the participants with highest PTBW values were V13 (PTBW = 143 Nm/kg), V12 (PTBW = $116 \mathrm{Nm} / \mathrm{kg}$ ), and V8 $(\mathrm{PTBW}=134 \mathrm{Nm} / \mathrm{kg}$ ) for the left, center, and right position, respectively, while participant V7 had the highest PTBW $(137 \mathrm{Nm} /$ $\mathrm{kg}$ ) among setters and libero players. Therefore, playing in the left position was associated with the highest PTBW of the shoulder, while playing in the center position was associated with the lowest PTBW. Participant V1 exhibited a low ratio (31\%) between internal and external rotation of the shoulder, while participants V3 and V14 exhibited a high ratio (75\% and 69\%, respectively), suggesting muscle imbalance. Among these, only participant V3 reported having shoulder injury and associated shoulder pain.

With respect to the isokinetic muscle function in the lumbar joints, participant V4 had the lowest power (PTBW $=301 \mathrm{Nm} /$ $\mathrm{kg}$ ), while participant V4 had the highest power (PTBW $=468$ $\mathrm{Nm} / \mathrm{kg}$ ). When considering the playing position, the participants with the highest PTBW were V4 (PTBW $=468 \mathrm{Nm} / \mathrm{kg})$, V8 $(\mathrm{PTBW}=456 \mathrm{Nm} / \mathrm{kg}$ ), and V10 (PTBW = $402 \mathrm{Nm} / \mathrm{kg})$ for the left, right, and center position, respectively, while participant V6 had the highest PTBW among setters and libero players (PTBW = $447 \mathrm{Nm} / \mathrm{kg}$ ). Therefore, playing in the left position was associated with the highest PTBW of the lumbar joints, while playing in the center position was associated with the lowest PTBW. A total of 4 out of 14 participants (V4, V5, V8, and V11) exhibited a low ratio $(<80 \%)$ of extension and flexion in the lower back, suggesting muscle imbalance.

With respect to isokinetic muscle function in the knee, we found that the PTBW was generally higher in the right knee than in the left. Participant V4 had the highest PTBW $(378 \mathrm{Nm} / \mathrm{kg}$ ) of the right knee, while participant V10 had the lowest PTBV (148 $\mathrm{Nm} / \mathrm{kg}$ ). When considering the playing position, the participants 
Table 2. Shoulder joint isokinetic muscle function assessment

\begin{tabular}{|c|c|c|c|c|c|}
\hline $\begin{array}{l}\text { Player's } \\
\text { position }\end{array}$ & Rotation & $\begin{array}{l}\text { Peak } \\
\text { torque } \\
(\mathrm{Nm})\end{array}$ & $\begin{array}{c}\text { Peak } \\
\text { torque/\% } \\
\text { BW } \\
\text { (Nm/kg) }\end{array}$ & $\begin{array}{c}\text { Average } \\
\text { power per } \\
\text { repetition } \\
\text { (Nm) }\end{array}$ & $\begin{array}{c}\text { Average } \\
\text { power per } \\
\text { repetition } / \% \\
\text { BW (Nm/kg) }\end{array}$ \\
\hline \multirow[t]{3}{*}{ V1 (L) } & Internal rotation & 114 & 137 & 90 & 108 \\
\hline & External rotation & 35 & 42 & 23 & 29 \\
\hline & Ratio & \multicolumn{2}{|c|}{31} & \multicolumn{2}{|r|}{26} \\
\hline \multirow[t]{3}{*}{ V2 (L) } & Internal rotation & 111 & 125 & 89 & 99 \\
\hline & External rotation & 54 & 60 & 42 & 46 \\
\hline & Ratio & 49 & & 47 & \\
\hline \multirow[t]{3}{*}{ V3 (L) } & Internal rotation & 98 & 116 & 79 & 92 \\
\hline & External rotation & 73 & 86 & 51 & 59 \\
\hline & Ratio & \multicolumn{2}{|c|}{75} & \multicolumn{2}{|r|}{65} \\
\hline \multirow[t]{3}{*}{ V4 (L) } & Internal rotation & 95 & 122 & 80 & 103 \\
\hline & External rotation & 52 & 66 & 40 & 53 \\
\hline & Ratio & \multicolumn{2}{|r|}{54} & \multicolumn{2}{|r|}{50} \\
\hline \multirow[t]{3}{*}{ V5 (R) } & Internal rotation & 107 & 131 & 90 & 110 \\
\hline & External rotation & 58 & 72 & 38 & 46 \\
\hline & Ratio & 54 & & 42 & \\
\hline \multirow[t]{3}{*}{ V6 (Li) } & Internal rotation & 100 & 128 & 87 & 112 \\
\hline & External rotation & 58 & 75 & 44 & 57 \\
\hline & Ratio & \multicolumn{2}{|r|}{58} & \multicolumn{2}{|r|}{51} \\
\hline \multirow[t]{3}{*}{ V7 (S) } & Internal rotation & 104 & 137 & 80 & 103 \\
\hline & External rotation & 54 & 72 & 43 & 55 \\
\hline & Ratio & \multicolumn{2}{|r|}{52} & \multicolumn{2}{|r|}{54} \\
\hline \multirow[t]{3}{*}{ V8 (R) } & Internal rotation & 113 & 134 & 92 & 110 \\
\hline & External rotation & 66 & 77 & 57 & 68 \\
\hline & Ratio & 59 & & 62 & \\
\hline \multirow[t]{3}{*}{ V9 (S) } & Internal rotation & 96 & 125 & 77 & 99 \\
\hline & External rotation & 50 & 66 & 35 & 44 \\
\hline & Ratio & \multicolumn{2}{|c|}{52} & \multicolumn{2}{|r|}{45} \\
\hline \multirow[t]{3}{*}{ V10 (C) } & Internal rotation & 100 & 101 & 79 & 81 \\
\hline & External rotation & 50 & 51 & 32 & 33 \\
\hline & Ratio & \multicolumn{2}{|r|}{50} & & 41 \\
\hline V11 (L) & Internal rotation & 118 & 143 & 92 & 112 \\
\hline & External rotation & 61 & 75 & 38 & 46 \\
\hline & Ratio & & 52 & & 41 \\
\hline V12 (C) & Internal rotation & 117 & 116 & 96 & 97 \\
\hline & External rotation & 62 & 63 & 43 & 44 \\
\hline & Ratio & & 53 & & 45 \\
\hline V13 (L) & Internal rotation & 127 & 149 & 101 & 119 \\
\hline & External rotation & 57 & 66 & 42 & 48 \\
\hline & Ratio & & 45 & & 42 \\
\hline V14 (L) & Internal rotation & 87 & 104 & 69 & 81 \\
\hline & External rotation & 60 & 72 & 45 & 53 \\
\hline & Ratio & & 69 & & 65 \\
\hline Total & Internal rotation & 99.8 & 126.2 & 85.8 & 101.9 \\
\hline (mean) & External rotation & 56.4 & 67 & 40.92 & 48.6 \\
\hline & Ratio & & 53.2 & & 47.8 \\
\hline
\end{tabular}

The volleyball players' position codes are: $C$, center; $L$, left; $R$, right; $S$, setter. BW, body weight; $\mathrm{V}$, volleyball player. with the highest PTBW were V4 (PTBW $=378 \mathrm{Nm} / \mathrm{kg})$, V8 $(\mathrm{PTBW}=313 \mathrm{Nm} / \mathrm{kg}$ ), and V12 (PTBW $=250 \mathrm{Nm} / \mathrm{kg}$ ) for the left, right, and center position, respectively, while participant $\mathrm{V} 7$ had the highest PTBW among setters and libero players (PTBW = $319 \mathrm{Nm} / \mathrm{kg}$ ). Therefore, playing in the left position was associated with the highest PTBW, while playing in the center position was associated with the lowest PTBW.

Of the 14 participants, a total of 8 (V1, V2, V4, V5, V10, V12, $\mathrm{V} 13$, and V14) had left-right extension deviation of $>10 \%$, while 4 (V1, V4, V7, and V13) had left-right flexion deviation. Moreover, considering that the normal extension and flexion ratio is $50 \%-$ $70 \%$, a total of 4 participants (V1, V5, V10, and V11), showed imbalance on the right side, while 5 participants (V1, V2, V5, V11, and V14) showed imbalance on the left side. Among these, there were two participants with PTBW of $<200 \mathrm{Nm} / \mathrm{kg}$, specifically: participant V10 among center position players (PTBW $=149 \mathrm{Nm} /$ $\mathrm{kg}$ ), and participant V1 among left position players (PTBW $=188$ $\mathrm{Nm} / \mathrm{kg}$ ).

\section{DISCUSSION}

Assessments of muscle strength have been conducted using various isometric, isotonic, and isokinetic exercise methods. It was suggested that isokinetic exercise using an isokinetic dynamometer allows for a more objective and accurate assessment (Hislop and Perrine, 1967) this was later proven by Thistle et al. (1967). During isokinetic exercise, which has a predefined exercise speed, when the muscle strength is too high, or the exercise speed exceeds the limit predefined in the machine, the machine applies a resistance force equivalent to the surpassing amount. This resistance force is considered to expresses the force generated in the muscles, and is stored in the machine as torque force. Moreover, unlike isometric or isotonic exercises, the isokinetic exercise has the advantage of generating maximum contraction for the entire range of motion (ROM) (Hislop and Perrine, 1967). Thus, isokinetic exercise can objectively and accurately compare the bilateral muscle strengths of a particular joint, as well as the agonistic and antagonistic muscle strengths of a single joint. Further, this technique also allows for evaluating the strength in relation to BW. Moreover, the exercise speed can be increased as the muscle strength increases in order to allow for a gradually increasing intensity during exercise and training (Gilliam et al., 1979; James et al., 2014; Kim and Youn, 2005; Rodríguez-Ruiz et al., 2014; Rosene et al., 2001).

The optimal ratio between internal and external rotation in the 
Table 3. Knee joint isokinetic muscle function assessment

\begin{tabular}{|c|c|c|c|c|c|c|c|c|c|c|c|}
\hline \multirow{2}{*}{$\begin{array}{l}\text { Player's } \\
\text { position }\end{array}$} & \multirow{2}{*}{ Imbalance } & \multicolumn{3}{|c|}{ Peak torque (Nm) } & \multicolumn{2}{|c|}{$\mathrm{PT} / \% \mathrm{BW}(\mathrm{Nm} / \mathrm{kg})$} & \multicolumn{3}{|c|}{ Average power per repetition (Nm) } & \multicolumn{2}{|c|}{$\mathrm{APR} / \% \mathrm{BW}(\mathrm{Nm} / \mathrm{kg})$} \\
\hline & & $\mathrm{R}$ & $L$ & Ratio & $\mathrm{R}$ & L & $\mathrm{R}$ & L & Ratio & $\mathrm{R}$ & L \\
\hline \multirow[t]{3}{*}{ V1 (L) } & EX & 155 & 89 & 57 & 188 & 107 & 104 & 61 & 60 & 125 & 75 \\
\hline & FLEX & 122 & 107 & 88 & 146 & 128 & 91 & 80 & 89 & 110 & 97 \\
\hline & Ratio & 79 & 120 & - & 77.6 & 119 & 88 & 131 & - & 88 & 129 \\
\hline \multirow[t]{3}{*}{ V2 (L) } & EX & 205 & 156 & 76 & 229 & 176 & 126 & 103 & 82 & 141 & 116 \\
\hline & FLEX & 140 & 129 & 92 & 158 & 143 & 105 & 91 & 87 & 119 & 101 \\
\hline & Ratio & 68 & 83 & - & 69 & 81.2 & 83 & 88 & - & 84.4 & 87 \\
\hline \multirow[t]{3}{*}{ V3 (L) } & EX & 235 & 240 & 98 & 277 & 283 & 138 & 152 & 91 & 163 & 180 \\
\hline & FLEX & 134 & 137 & 99 & 158 & 161 & 92 & 98 & 94 & 108 & 116 \\
\hline & Ratio & 57 & 57 & - & 56.6 & 57 & 67 & 64 & - & 66.2 & 64 \\
\hline \multirow[t]{3}{*}{ V4 (L) } & EX & 290 & 217 & 75 & 378 & 283 & 193 & 147 & 76 & 251 & 191 \\
\hline & FLEX & 186 & 145 & 78 & 241 & 188 & 126 & 106 & 84 & 165 & 138 \\
\hline & Ratio & 64 & 67 & - & 64 & 66.4 & 65 & 72 & - & 66 & 72 \\
\hline \multirow[t]{3}{*}{ V5 (R) } & EX & 217 & 119 & 55 & 265 & 146 & 146 & 92 & 63 & 178 & 112 \\
\hline & FLEX & 170 & 153 & 90 & 206 & 188 & 120 & 110 & 92 & 147 & 134 \\
\hline & Ratio & 78 & 128 & - & 78 & 128 & 82 & 120 & - & 83 & 119 \\
\hline \multirow[t]{3}{*}{ V6 (Li) } & EX & 241 & 217 & 90 & 310 & 280 & 171 & 150 & 68 & 220 & 193 \\
\hline & FLEX & 159 & 144 & 90 & 203 & 185 & 117 & 109 & 93 & 149 & 141 \\
\hline & Ratio & 66 & 66 & - & 65 & 66 & 73 & 73 & - & 68 & 73 \\
\hline \multirow[t]{3}{*}{ V7 (S) } & EX & 245 & 224 & 91 & 319 & 292 & 165 & 138 & 84 & 215 & 180 \\
\hline & FLEX & 125 & 142 & 88 & 161 & 185 & 94 & 102 & 92 & 123 & 132 \\
\hline & Ratio & 51 & 64 & - & 50.4 & 63.3 & 57 & 74 & - & 57 & 73 \\
\hline \multirow[t]{3}{*}{ V8 (R) } & EX & 264 & 283 & 94 & 313 & 337 & 171 & 183 & 93 & 202 & 218 \\
\hline & FLEX & 182 & 174 & 96 & 215 & 206 & 114 & 115 & 99 & 136 & 136 \\
\hline & Ratio & 69 & 61 & - & 69 & 61 & 67 & 63 & - & 67 & 62 \\
\hline \multirow[t]{3}{*}{ V9 (S) } & EX & 195 & 201 & 97 & 250 & 259 & 122 & 144 & 85 & 156 & 185 \\
\hline & FLEX & 132 & 136 & 97 & 170 & 173 & 97 & 92 & 95 & 125 & 119 \\
\hline & Ratio & 67 & 68 & - & 68 & 67 & 80 & 64 & - & 80.1 & 64 \\
\hline \multirow[t]{3}{*}{ V10 (C) } & EX & 146 & 209 & 70 & 149 & 215 & 82 & 112 & 73 & 84 & 114 \\
\hline & FLEX & 122 & 118 & 97 & 125 & 119 & 75 & 76 & 99 & 77 & 77 \\
\hline & Ratio & 83 & 56 & - & 84 & 55 & 91 & 65 & - & 92 & 68 \\
\hline \multirow[t]{3}{*}{ V11 (L) } & EX & 274 & 256 & 93 & 331 & 310 & 186 & 154 & 83 & 224 & 187 \\
\hline & FLEX & 129 & 125 & 97 & 155 & 152 & 91 & 85 & 93 & 110 & 103 \\
\hline & Ratio & 47 & 49 & - & 47 & 49 & 49 & 55 & - & 49 & 55 \\
\hline \multirow[t]{3}{*}{ V12 (C) } & EX & 250 & 206 & 82 & 250 & 209 & 170 & 149 & 88 & 171 & 149 \\
\hline & FLEX & 151 & 136 & 90 & 152 & 137 & 102 & 98 & 96 & 103 & 99 \\
\hline & Ratio & 60 & 66 & - & 61 & 66 & 60 & 66 & - & 60 & 66 \\
\hline \multirow[t]{3}{*}{ V13 (L) } & EX & 285 & 220 & 77 & 334 & 259 & 210 & 149 & 71 & 246 & 176 \\
\hline & FLEX & 151 & 129 & 85 & 176 & 152 & 105 & 94 & 90 & 123 & 110 \\
\hline & Ratio & 53 & 59 & - & 53 & 59 & 50 & 63 & - & 50 & 63 \\
\hline \multirow[t]{3}{*}{ V14 (L) } & EX & 252 & 202 & 80 & 301 & 241 & 178 & 145 & 81 & 211 & 171 \\
\hline & FLEX & 165 & 152 & 92 & 197 & 182 & 120 & 115 & 96 & 143 & 136 \\
\hline & Ratio & 66 & 75 & - & 65 & 81 & 67 & 79 & - & 68 & 80 \\
\hline Total (mean) & EX & 232.4 & 196.4 & 84.5 & 278.1 & 242.6 & 154.4 & 134.2 & 78.4 & 184.7 & 160.5 \\
\hline & FLEX & 147.7 & 137.6 & 93.1 & 175.9 & 164.2 & 103.5 & 90.3 & 92.7 & 124.1 & 117 \\
\hline & Ratio & 64.8 & 72.7 & - & 64.8 & 72.7 & 69.9 & 76.9 & - & 69.9 & 76.7 \\
\hline
\end{tabular}

The volleyball players' position codes are: C, center; L, left; R, right; $S$, setter. BW, body weight; EX, extension; FLEX, flexion. 
Table 4. Trunk joint isokinetic muscle function assessment:

\begin{tabular}{|c|c|c|c|c|c|}
\hline $\begin{array}{l}\text { Player's } \\
\text { position }\end{array}$ & Imbalance & $\begin{array}{l}\text { Peak } \\
\text { torque } \\
(\mathrm{Nm})\end{array}$ & $\begin{array}{c}\text { Peak } \\
\text { torque/\% } \\
\text { BW } \\
(\mathrm{Nm} / \mathrm{kg})\end{array}$ & $\begin{array}{c}\text { Average } \\
\text { power per } \\
\text { repetition } \\
\text { (Nm) }\end{array}$ & $\begin{array}{c}\text { Average } \\
\text { power per } \\
\text { repetition/\% } \\
\text { BW (Nm/kg) }\end{array}$ \\
\hline \multirow[t]{3}{*}{ V1 (L) } & EX & 335 & 405 & 218 & 264 \\
\hline & FLEX & 358 & 432 & 288 & 347 \\
\hline & Ratio & \multicolumn{2}{|c|}{106} & \multicolumn{2}{|r|}{7} \\
\hline \multirow[t]{3}{*}{ V2 (L) } & EX & 344 & 387 & 265 & 297 \\
\hline & FLEX & 311 & 349 & 253 & 284 \\
\hline & Ratio & \multicolumn{2}{|c|}{90} & \multicolumn{2}{|r|}{95} \\
\hline \multirow[t]{3}{*}{ V3 (L) } & EX & 296 & 349 & 228 & 270 \\
\hline & FLEX & 282 & 334 & 232 & 275 \\
\hline & Ratio & \multicolumn{2}{|c|}{95} & \multicolumn{2}{|r|}{98} \\
\hline \multirow[t]{3}{*}{ V4 (L) } & EX & 359 & 468 & 272 & 354 \\
\hline & FLEX & 248 & 322 & 220 & 286 \\
\hline & Ratio & \multicolumn{2}{|c|}{69} & \multicolumn{2}{|r|}{81} \\
\hline \multirow[t]{3}{*}{ V5 (R) } & EX & 317 & 384 & 251 & 303 \\
\hline & FLEX & 228 & 274 & 180 & 218 \\
\hline & Ratio & \multicolumn{2}{|c|}{72} & \multicolumn{2}{|r|}{72} \\
\hline \multirow[t]{3}{*}{ V6 (Li) } & EX & 347 & 447 & 235 & 325 \\
\hline & FLEX & 293 & 376 & 235 & 301 \\
\hline & Ratio & \multicolumn{2}{|c|}{84} & \multicolumn{2}{|r|}{93} \\
\hline \multirow[t]{3}{*}{ V7 (S) } & EX & 328 & 426 & 240 & 312 \\
\hline & FLEX & 296 & 384 & 244 & 316 \\
\hline & Ratio & \multicolumn{2}{|c|}{90} & \multicolumn{2}{|r|}{98} \\
\hline \multirow[t]{3}{*}{ V8 (R) } & EX & 384 & 456 & 232 & 275 \\
\hline & FLEX & 273 & 325 & 226 & 268 \\
\hline & Ratio & \multicolumn{2}{|c|}{71} & & 97 \\
\hline V9 (S) & EX & 343 & 441 & 238 & 305 \\
\hline & FLEX & 283 & 364 & 237 & 305 \\
\hline & Ratio & & 3 & & 100 \\
\hline V10 (C) & EX & 395 & 402 & 231 & 235 \\
\hline & FLEX & 389 & 396 & 285 & 292 \\
\hline & Ratio & & 9 & & 81 \\
\hline V11 (L) & EX & 344 & 447 & 236 & 308 \\
\hline & FLEX & 256 & 334 & 220 & 286 \\
\hline & Ratio & & 4 & & 93 \\
\hline V12 (C) & EX & 382 & 384 & 278 & 281 \\
\hline & FLEX & 366 & 370 & 300 & 303 \\
\hline & Ratio & & 6 & & 93 \\
\hline V13 (L) & EX & 287 & 337 & 222 & 262 \\
\hline & FLEX & 296 & 349 & 232 & 273 \\
\hline & Ratio & & 7 & & 96 \\
\hline V14 (L) & EX & 252 & 301 & 201 & 240 \\
\hline & FLEX & 292 & 346 & 223 & 266 \\
\hline & Ratio & & 36 & & 90 \\
\hline Total (mean) & EX & 339.5 & 402.4 & 239 & 287.9 \\
\hline & FLEX & 297.9 & 353.9 & 241 & 287.7 \\
\hline & Ratio & & 5.7 & & 90.1 \\
\hline
\end{tabular}

The volleyball players' position codes are: $\mathrm{C}$, center; $\mathrm{L}$, left; $\mathrm{R}$, right; $\mathrm{S}$, setter. BW, Body weight; EX, extension; FLEX, flexion. shoulder was shown to be $3: 2$; the optimal ration between trunk flexion and extension was shown to be 1:1; and the optimal ratio between knee flexion and extension was shown to be 2:3 (Dvir, 2004; Rosene et al., 2001). However, the ranges of ideal muscle strength ratio vary depending on the study. For the knees, the ratio of forces involved in extension to those involved in flexion should be at least $50 \%-70 \%$. Further, the force ratio between the dominant and nondominant sides should be of 1:1; however, a difference of $10 \%$ is considered as being within a normal range (Andrade Mdos et al., 2012; Cheung et al., 2012; Dirnberger et al., 2012; Elliott, 1978).

ROM used during trunk isokinetic testing varies depending on the study. Smith et al. (1985) used flexion range of $30^{\circ}-40^{\circ}$ and extension range of $15^{\circ}-20^{\circ}$, while Kim and Shin (1999) and Newton et al. (1993) applied flexion range of $80^{\circ}$, and Davies and Gould (1982) applied a ROM of $\geq 90^{\circ}$. However, the most effective ROM for studying trunk muscle strength and trunk exercise has not been suggested yet. In the present study, ROM was set to $80^{\circ}$ for flexion and $15^{\circ}$ for extension, in order to induce peak isokinetic flexion and extension. All participants were able to perform the exercise relatively easily within these ranges. The angular speed used to measure trunk isokinetic strength depends on the study. Particularly, with respect to the speed of isokinetic trunk flexion and extension, Parnianpour et al. (1988) stated that trunk flexion and extension speed of $60 \% \mathrm{sec}$ is appropriate for activities of daily living, while a speed of $30 \% \mathrm{sec}$ is appropriate for patients with lower back pain (Marras and Wongsam, 1986); if lower back injury is incomplete, measuring at $60^{\circ} / \mathrm{sec}$ would not represent a fully functional activity. Newton et al. (1993) stated that the ideal measurement should account for the exercise speeds of $60 \% / \mathrm{sec}$, $90 \% \mathrm{sec}$, and $120 \% \mathrm{sec}$. In the present study, the speed was set to $60 \% \mathrm{sec}$ for measuring the maximum muscle strength of the volleyball players.

There have been many studies on the extension and flexion strength of the trunk muscles, and the reported results have indicated that extension was stronger than flexion (Flint, 1958; Guilhem et al, 2014; Mayer et al., 1985; McNeill et al., 1980; Smidt et al., 1980). The reason for this is that the cross section during trunk extension is bigger than during flexion. Therefore, although the trunk extension to flexion ratio is known to be from 1.1:1 to 2.7:1 (Dvir, 2004; Smith et al., 1985; Wessel et al., 1992), in the case of volleyball players, at the moment of bending the lower back backwards and engaging in position for spiking or serving, maximum power is generated by the combination of power from flexion motion of the lower back and of the shoulders. Therefore, 
it would be possible to assume that the appropriate flexion to extension ratio for preventing lower back injury and for drawing out peak sports performance would be 1:1. However, the results of the present study showed that 13 of the 14 players exhibited greater strength for extension than for flexion. Moreover, results from measurements of 5 repetitions performed at the speed of $60 \% / \mathrm{sec}$ showed that 4 of the 14 players had a difference of $\geq 20 \%$ in the trunk flexion-to-extension ratio, showing a relative imbalance regarding the strengths for extension and flexion. This result supports the need for training programs focused on balance control. In order to understand which ratios would allow for better spike and serving skills during matches, studies on reference values for PTBW and extension and flexion strength ratio are needed. Most volleyball players use one arm the dominant to practice a lot of forceful spike and overhead serves during the training season.

Bahr and Krosshaug (2005) indicated that muscle imbalance causes damages to the joints by pulling down on the joints in an asymmetric manner (Meister and Andrews, 1993). Based on this, it is possible that having unbalanced internal to external rotation ratios is associated with higher risk of injury. Chung et al. (1987) compared the external and internal rotation muscle strengths of healthy Korean adults and found that the muscles responsible for internal rotation had higher strength than those responsible for external rotation. The results of Mayer et al. (1994) indicated that normal ratios of external to internal rotation strengths for the general population for $60 \%$ sec testing were 0.57 for the dominant side and 0.61 for the nondominant side in a concentric test. Wang et al. (2000) measured shoulder muscle strength of players on the English national volleyball team and found that the ratio of strength of the external rotator to that of the internal rotator muscle were approximately 1 for the dominant side and 0.67 for the non-dominant side in a concentric test.

In the present study, the difference in shoulder internal and external rotation ratio was $53.2 \%$, with internal rotation showing. Imbalance in shoulder internal-to-external rotation strength ratio was observed in 3 of the 14 players. In the results of the present study and in those of precedent studies, internal-to-external rotation strength ratios of volleyball players' shoulders were $3: 2$ for the dominant side, but 1:1 for the nondominant side. Accordingly, studies regarding internal and external rotation ratios are warranted in order to facilitate the prevention of shoulder injuries. Further, such studies, when focused on game performance, could help identify the minimal value of PTBW required for performing volleyball actions such as powerful spike and serving (James et al., 2014; Wang et al., 2000).
The major agonistic muscles recruited for those movements are the hamstrings and the quadriceps, with the back of the legs and the tibialis anterior also serving as contributors. Moreover, for spike actions, a greater coordination between the major back muscles and the muscles of the shoulder area must be achieved (Reeser et al., 2006; Seminati and Minetti, 2013)

Imbalance signifies possible additional risk, such as soft tissue damage, regardless of the various causes of injury (Zakas et al., 1995). Of course, there are limitations in relating the isokinetic muscle strength, measured mechanically, to the possibility of injury in an actual match or during practice situations. However, in the field of sports medicine, this relation is commonly very high. In particular, Aagaard et al. (1998) claimed that having an isokinetic muscle strength ratio of $\leq 60 \%$ at low angular speed increased the risk of injury, while Ayala et al. (2012) reported that increased quadriceps strength from training can reduce activation of antagonistic muscles of the hamstrings. Such low isokinetic balance ratio can be a cause of increased risk of knee injury by exerting tensional stress on the anterior cruciate ligament due to a decrease in joint stabilizing muscle strength (Cheung et al., 2012; Rosen et al., 2001).

Three out of 14 players had a shoulder flexion-to-extension ratio of 2:3. When considering the knees, shoulders, and lower back, the region for which the highest number of players exhibited imbalance was the knee joints. Players of the left position exhibited the highest peak torque values for the shoulders, knees, and lower back, while players of the center position exhibited the lowest peak torque for all regions. In a study by Chae et al. (2002), the mean knee kinetic $60 \%$ sec PTBW of volleyball players who play on attacking positions was 329, while those of setters and libero players were 310 and 314 , respectively. However, in the present study, left side attackers exhibited a PTBW of 291, while the highest value of PTBW was 378, for the participant V4, which indicates significant variation among attackers.

In a study by Kim and Choi (2007), the national team players showed normal reference values, with a PTBW of 270 , left-right deviation of $<10 \%$, and an extension/flexion ratio of $55 \%$. In the present study, 8 out of 14 participants had left-right deviation $\geq 10 \%$, while 4 out of 14 had muscle imbalance (i.e., an extension/flexion ratio outside the range 50\%-70\%). We may conclude that the volleyball players included in the present study should undergo a rehabilitation program to recover from knee injury.

Participating in elite sports competitions requires continuous, quantitative improvement in the angular torque and angle for which maximum muscle strength is manifested, as these parame- 
ters allow superior execution of actions during which maximum muscle strength needs to be generated quickly. The underlying mechanisms were proposed by Thorstensson et al. (1976), and involve force, muscle contraction speed, and muscle fiber relationships. Specifically, the maximum force generated depends on the number and type of muscle fibers recruited, as well as on the speed and cooperativity of nerve impulses. Moreover, recruitment of the nerve-muscle unit is very important for increasing the efficiency of movement, and this is reported to be highly associated with the angle at which maximum muscle strength is manifested (Moffroid et al, 1969). Taken together, these results suggest that the angle at which maximum muscle strength is manifested plays a very important role in sports performance. Together with maximum muscle strength, this angle affects mean power and muscle endurance. Since power represents the value of work divided by time, muscle strength (i.e., force) must be increased above all others, and must be generated in the initial stage of the effort in order to achieve increased power. In the present study, an isokinetic dynamometer was used to assess the shoulder, lower back, and knee muscle functions of male players of the Korean national volleyball team. The results showed that the number of volleyball players with differences between the strength of the bilateral knee muscles, and between the strength of the hamstrings and quadriceps muscles was higher than the number of players with differences between the strength of the shoulder internal and external rotation muscles, and higher than the number of players with differences between the strength of the lower back extension and flexion muscles. These findings may suggest that the risk of knee injury is greater than that of shoulder or lower back injury. With respect to player positions, players who play in the center position exhibited the lowest muscle function for all the 3 studied categories (shoulders, knees, and lower back). Future studies are warranted to research the reference values of optimal PTBW, which can be used for injury prevention and for executing powerful spikes and servings.

\section{CONFLICT OF INTEREST}

No potential conflict of interest relevant to this article was reported.

\section{REFERENCES}

Aagaard H, Jørgensen U. Injuries in elite volleyball. Scand J Med Sci Sports 1996;6:228-232.
Aagaard H, Scavenius M, Jørgensen U. An epidemiological analysis of the injury pattern in indoor and in beach volleyball. Int J Sports Med 1997;18:217-221.

Aagaard P, Simonsen EB, Magnusson SP, Larsson B, Dyhre-Poulsen P. A new concept for isokinetic hamstring: quadriceps muscle strength ratio. Am J Sports Med 1998;26:231-237.

Andrade Mdos S, De Lira CA, Koffes Fde C, Mascarin NC, Benedito-Silva AA, Da Silva AC. Isokinetic hamstrings-to-quadriceps peak torque ratio: the influence of sport modality, gender, and angular velocity. J Sports Sci 2012;30:547-553.

Ayala F, De Ste Croix M, Sainz de Baranda P, Santonja F. Absolute reliability of hamstring to quadriceps strength imbalance ratios calculated using peak torque, joint angle-specific torque and joint ROM-specific torque values. Int J Sports Med 2012;33:909-916.

Bahr R, Krosshaug T. Understanding injury mechanisms: a key component of preventing injuries in sport. Br J Sports Med 2005;39:324-329.

Brooks GA, Fahey TD. Fundamentals of human performance. New York: Collier Macmillan; 1987. p. 35-40.

Chae CH, Keon SI, Kwon TW. A study on the standard of specific physical fitness about position of volleyball players. Korean J Sports Sci 2002;11:713-722.

Cheung RT, Smith AW, Wong del P. H:Q ratios and bilateral leg strength in college field and court sports players. J Hum Kinet 2012;33:63-71.

Chung MY, Ha KI, Hahn SH, Ryu JW. Analysis of internal rotator-external rotator muscle of the shoulder with Cybex II. J Korean Orthop Assoc 1987;22:304-309.

Davies GJ, Gould JA. Trunk testing using a prototype cybex II lsokinetic dynamometer stabilization system. J Orthop Sports Phys Ther 1982;3: 164-170.

Dirnberger J, Weisinger HP, Kösters A, Müller E, Reproducibility for isometric and isokinetic maximum knee flexion and extension measurements using the Iso Med 2000-dynamometer. Isokinet Exerc Sci 2012;20:149-153.

Dvir Z. Physiological and biomechanical aspects of isokinetics. In: Dvir Z, editor. Isokinetics: muscle testing, interpretation and clinical applications. Now York: Churchill Livingstone; 2004. p. 137-165.

Elliott J. Assessing muscle strength isokinetically. JAMA 1978;240:2408, 2410.

Flint MM. Effect of increasing back and abdominal strength in low back pain. Res Quart Exerc Sport 1958;29:160-171.

Gilliam TB, Sady SP, Freedson PS, Villanacci J. Isokinetic torque levels for high school football players. Arch Phys Med Rehabil 1979;60:110-114.

Guilhem G, Giroux C, Couturier A, Maffiuletti NA. Validity of trunk extensor and flexor torque measurements using isokinetic dynamometry. J Electromyogr Kinesiol 2014;24:986-993. 
Han DY, Kim KC, Hyun KS. Effects of specificity core balance training on isokinetic muscular functions in high school male volleyball players. J Sport Leis Stud 2011;46:1181-1189.

Hislop HJ, Perrine JJ. The isokinetic concept of exercise. Phys Ther 1967;47:114-117.

James LP, Kelly VG, Beckman EM. Injury risk management plan for volleyball athletes. Sports Med 2014;44:1185-1195.

Jespersen M, Potvin AN, Thorson K, Apostolopoulos N. The great body ball handbook. Surrey, B.C.: Productive Fitness Products; 2000.

Kim DY, Youn SW. Comparison the isokinetic exercise test of various sport events athletes. Korean J Sports SCi 2005;16:1-14.

Kim HD, Choi KH. The isokinetic knee muscle strength and the anaerobic between women's national volleyball team player and junior national volleyball team players. J Sports Leis Stud 2007;31:1013-1024.

Kim SH, Shin BC. A study on the norm-reference criteria for isokinetic functional strength of the trunk for adults. Kor Sport Research. 1999; 10:123-134.

Lamb RD. Physiology of exercise: response \& adatation. New York: Collier Macmillan Publishers; 1984.

MacLaren D. Court games: volleyball and basketball. In: Reilly T, Secher N, Snell P, Williams C. Physiology of sports. London: E \& FN Spon; 1990. p. 376-409.

Mayer F, Horstmann T, Röcker K, Heitkamp HC, Dickhuth HH. Normal values of isokinetic maximum strength, the strength/velocity curve, and the angle at peak torque of all degrees of freedom in the shoulder. Int J Sports Med 1994;15 Suppl 1:S19-25.

Mayer TG, Smith SS, Keeley J, Mooney V. Quantification of lumbar function. Part 2: Sagittal plane trunk strength in chronic low-back pain patients. Spine (Phila Pa 1976) 1985;10:765-772.

Marras WS, Wongsam PE. Flexibility and velocity of the normal and impaired lumbar spine. Arch Phys Med Rehabil 1986;67:213-217.

McNeill T, Warwick D, Andersson G, Schultz A. Trunk strengths in attempted flexion, extension, and lateral bending in healthy subjects and patients with low-back disorders. Spine (Phila Pa 1976) 1980;5: 529-538.

Meister K, Andrews JR. Classification and treatment of rotator cuff injuries in the overhand athlete. J Orthop Sports Phys Ther 1993;18:413421.

Moffroid M, Whipple R, Hofkosh J, Lowman E, Thistle H. A study of isokinetic exercise. Phys Ther 1969;49:735-747.

Newton M, Thow M, Somerville D, Henderson I, Waddell G. Trunk strength testing with iso-machines. Part 2: experimental evaluation of the cybex II back testing system in normal subjects and patients with chronic low back pain. Spine (Phila Pa 1976) 1993;18:812-824.

Parnianpour M, Nordin M, Kahanovitz N, Frankel V. 1988 Volvo award in biomechanics. The triaxial coupling of torque generation of trunk muscles during isometric exertions and the effect of fatiguing isoinertial movements on the motor output and movement patterns. Spine (Phila Pa 1976) 1988;13:982-992.

Reeser JC, Verhagen E, Briner WW, Askeland TI, Bahr R. Strategies for the prevention of volleyball related injuries. Br J Sports Med 2006;40: 594-600.

Rodríguez-Ruiz D, Diez-Vega I, Rodríguez-Matoso D, Fernandez-del-Valle M, Sagastume R, Molina JJ. Analysis of the response speed of musculature of the knee in professional male and female volleyball players. Biomed Res Int 2014;2014:239708.

Rosene JM, Fogarty TD, Mahaffey BL. Isokinetic Hamstrings:quadriceps ratios in intercollegiate athletes. J Athl Train 2001;36:378-383.

Seminati E, Minetti AE. Overuse in volleyball training/practice: a review on shoulder and spine-related injuries. Eur J Sport Sci 2013;13:732-743.

Smidt GL, Amundsen LR, Dostal WF. Muscle strength at the trunk. J Orthop Sports Phys Ther 1980;1:165-170.

Smith SS, Mayer TG, Gatchel RJ, Becker TJ. Quantification of lumbar function. Part 1: Isometric and multispeed isokinetic trunk strength measures in sagittal and axial planes in normal subjects. Spine (Phila Pa 1976) 1985;10:757-764.

Stickley CD, Hetzler RK, Freemyer BG, Kimura IF. Isokinetic peak torque ratios and shoulder injury history in adolescent female volleyball athletes. J Athl Train 2008;43:571-577.

Thistle HG, Hislop HJ, Moffroid M, Lowman EW. Isokinetic contraction: a new concept of resistive exercise. Arch Phys Med Rehabil 1967;48: 279-282.

Thorstensson A, Grimby G, Karlsson J. Force-velocity relations and fiber composition in human knee extensor muscles. J Appl Physiol 1976;40: $12-16$.

Wang HK, Macfarlane A, Cochrane T. Isokinetic performance and shoulder mobility in elite volleyball athletes from the United Kingdom. Br J Sports Med 2000;34:39-43.

Wessel J, Ford D, van Driesum D. Measurement of torque of trunk flexors at different velocities. Scand J Rehabil Med 1992;24:175-180.

Zakas A, Mandroukas K, Vamvakoudis E, Christoulas K, Aggelopoulou $\mathrm{N}$. Peak torque of quadriceps and hamstring muscles in basketball and soccer players of different divisions. J Sports Med Phys Fitness 1995;35:199-205. 